\title{
GEOSUL
}

\section{O ALUNO BRASIGUAIO NO CONTEXTO DO MERCOSUL: O MOVIMENTO E A INVISIBILIDADE COMO TÁTICA DE SOBREVIVÊNCIA NA TRÍPLICE FRONTEIRA (BR, PY E AR - 2002-2011)}

\author{
Margarete Frasson ${ }^{1}$ \\ Marli Terezinha Szumilo Schlosser ${ }^{2}$
}

Resumo: O desenvolvimento regional proposto pelo Mercosul intensificou as relações entre Brasil e Paraguai (Tríplice Fronteira - BR, AR e PY). Essas relações concebem direitos aos sujeitos migrantes de cada lado da fronteira, mas podem também agir com perversidade sobre os portadores de cultura híbrida e minoritária, pela invisibilidade de sua situação intermediária. Este artigo estuda o movimento do aluno brasiguaio, no período de 2002 a 2011, em quatro estabelecimentos públicos de ensino localizados em Santa Terezinha de Itaipu, nessa região fronteiriça do lado brasileiro. Os formulários autopreenchidos pelos alunos e a análise de seus prontuários evidenciam a mobilidade e a invisibilidade criadas pelo desenvolvimento regional. Constata-se que essas estratégias são utilizadas pelo migrante como tática de sobrevivência na fronteira.

Palavras-chave: Mercosul; Aluno brasiguaio; Fronteira.

\section{THE STUDENTS BRAZIGUAYAN IN THE CONTEXT OF MERCOSUR: THE MOVEMENT AND INVISIBILITY AS A SURVIVAL TACTIC IN THE TRIPLE FRONTIER (BR, PY E AR - 2002-2011)}

\begin{abstract}
Regional development proposed by the Bloc Mercosur Economic international politics, increased the movement in the Triple Frontier (BR, AR and PY) of properties, services and people. Relations between Brazil and Paraguay has intensified. These relations define the immigrants as subjects with full right of each side of the frontier, but they (relations) can also act on the perversity of hybrid culture immigrants and minority, by the invisibility of their intermediate situation and not provided or established legally. This article studies the braziguayan student movement from 2002 to 2011 in four public schools located in Santa Terezinha de Itaipu, the border region of the Triple Frontier. Through self-report form, the analysis of these students charts, mobility is evident, the invisibility created by the regional development. It is Faced that these strategies (mobility, invisibility) are used by the immigrant as a tactic of survival on the frontier.
\end{abstract}

Keywords: Mercosur; Students braziguayan; Frontier.

\footnotetext{
${ }^{1}$ Professora do quadro próprio do Magistério paranaense. Mestre em Geografia, Universidade Estadual do Oeste do Paraná - UNIOESTE- Campus de Francisco Beltrão. Integrante do Laboratório de Ensino de Geografia LEG e Grupo e Linha de Pesquisa Ensino e Práticas de Geografia - ENGEO, número 34953/2011, cadastrado junto à Universidade Estadual do Oeste do Paraná - Unioeste. (marga.sti @ hotmail.com)

${ }_{2}^{2}$ Doutora em Geografia, professora do curso de Geografia da UNIOESTE - Campus de Marechal Cândido Rondon. Integrante do Laboratório de Ensino de Geografia - LEG e Grupo e Linha de Pesquisa Ensino e Práticas de Geografia - ENGEO, número 34953/2011, cadastrado junto à Universidade Estadual do Oeste do Paraná - Unioeste (marlisch20@ hotmail.com)
} 


\section{EL ALUMNO BRASIGUAYO EN EL CONTEXTO DEL MERCOSUR: EL MOVIMIENTO Y LA INVISIBILIDAD COMO TÁCTICA DE SUPERVIVENCIA EN EL TRIPLE FRONTERA (BR, PY Y AR - 2002-2011)}

Resumen: El desarrollo regional propuesto por Mercosur intensificó las relaciones entre Brasil y Paraguay (Tripe Frontera - BR, AR y PY). Esas relaciones, conciben derechos a los sujetos migrantes de cada lado de la frontera, mas, también pueden actuar con perversidad sobre los portadores de cultura híbrida y minoritaria, por la invisibilidad de su situación intermediaria. Este artículo estudia el movimiento del alumno brasiguayo en el periodo de 2002 a 2011, en cuatro establecimientos públicos de enseñanza ubicados en Santa Terezinha de Itaipu, en esta región de frontera del lado brasilero. Los formularios auto rellenado por los alumnos y el análisis de sus prontuarios, evidencia la movilidad y la invisibilidad creada por el desarrollo regional. Se constata que dichas estrategias son utilizadas por el migrante como táctica de supervivencia en la frontera.

Palabras-clave: Mercosur; Alumno brasiguayo; Frontera.

\section{INTRODUÇÃO}

O período de 2002 a 2011 corresponde à segunda década de existência do Setor Educacional do Mercosul (SEM). Os alunos do ensino fundamental que estudaram nesse período no Paraguai e no Brasil (alunos brasiguaios), em 2012 encontram-se, portanto, matriculados do segundo ano, séries iniciais (fundamental I) ao terceiro ano do ensino médio.

O campo de estudo é constituído por duas escolas municipais ${ }^{3}$ que atendem ao fundamental I e dois colégios ${ }^{4}$ que trabalham com alunos do fundamental II e do ensino médio.

A coleta de dados e informações demanda utilizar formulários autopreenchidos pelos 1419 alunos para identificar quem são e onde se encontram os alunos brasiguaios nos quatro estabelecimentos de ensino e anos escolares. Entre esses alunos, das 69 turmas, encontravamse 133 alunos com experiência de haver estudado no Paraguai e, no momento da pesquisa, matriculados em escola brasileira.

Os professores presentes nas 69 turmas pesquisadas, ao preencherem o formulário, demonstraram a sua percepção quanto à existência ou não de alunos estrangeiros nas turmas por eles trabalhadas.

A análise dos prontuários dos 133 alunos identificados pelo formulário autopreenchido, e comprovado pela constatação individual (pesquisador/aluno), permitiu caracterizar a mobilidade desse grupo de migrantes na Tríplice Fronteira, especificamente entre Brasil e Paraguai. Também permitiu compreender a invisibilidade do aluno brasiguaio detectada nos formulários preenchidos pelos professores regentes de classe.

\footnotetext{
${ }^{3}$ Escola Municipal Monteiro Lobato e Escola Municipal Olímpio Sprícigo.

${ }^{4}$ Colégio Estadual Ângelo Antônio Benedet e Colégio Estadual Dom Manoel Könner.
} 
Assim, o presente texto constitui-se inicialmente por um referencial teórico sobre fronteira, referencial a partir do qual, pelos termos-chave utilizados por diferentes estudiosos, contextualiza a questão da "fronteira" em estudo e permite visualizar o objeto na conjuntura global. Na sequência se analisa a mobilidade do brasiguaio na fronteira caracterizando-a como busca por sobrevivência e se finaliza desmistificando a invisibilidade do aluno em sala de aula, onde o agir da escola, ao atender os processos legais propostos pelo SEM, favorece essa ação de invisibilidade. Leva-se em conta que a maioria desses alunos, enquanto residentes no Paraguai, estudou em escolas da área rural, em muitos casos sendo escolas mantidas pelas comunidades locais. Assim, esses estudantes ao chegarem, no Brasil, a uma escola localizada na área urbana, as relações são mais complexas, isso devido à interferência da cultura e dos espaços construídos e reconstruídos pelo capital hegemônico, onde a fronteira demarca historicidades desencontradas.

\section{A FRONTEIRA E O MOVIMENTO TEÓRICO}

O estudo sobre a dinâmica conceitual de fronteiras utilizado neste texto permite confirmar, segundo o Grupo RETIS ${ }^{5}$, que "As classificações e tipologias de fronteira-limite evoluíram da simples divisão natural-artificial para outras [...], até chegar àquelas com base na paisagem cultural". Nesse sentido, os conceitos de "território", de "limite" e de "fronteira" permitem visualizar a engrenagem que proporciona o movimento da/na fronteira, e nele contextualizar o espaço de estudo no qual está inserido o aluno brasiguaio.

A fronteira, para o ser humano, apresenta-se como “[...] espaço da alteridade, do encontro de temporalidades distintas, de conceitos e preconceitos, de línguas e culturas que ajustam uma identidade" (MARTIN, 1994, p. 16). O mais relevante para definir a fronteira é a situação de conflito social que ocorre no local, conflito devido à alteridade. Assim, "A linha imaginária [...] constitui elemento importante no campo de conflitos" (MÉLO, 2004, p. 144). A fronteira aparenta ser o lugar do encontro, mas, pela descoberta do outro, passa a ser um lugar de desencontro (MARTINS, 2009).

Então, ao perpassar os estudos sobre a fronteira por diferentes abordagens metodológicas e teóricas, utilizadas por diversas ciências e autores, vão surgindo novos conceitos de fronteira para elucidar o seu espaço. Neste sentido, para Santos (2004), ela se apresenta como fato diplomático, jurídico, fiscal, militar, político e financeiro. Neste caso, “[...] a fronteira [...] impõe, por necessidade do Estado, uma disjunção histórica, um corte que

\footnotetext{
${ }^{5}$ Disponível em: <http://acd.ufrj.br/fronteiras/pesquisa/fronteira/p02avul sos04.htm>. Acesso em: 3 set. 2013.
} 
institui uma diferença, que dificulta uma identidade fronteiriça, e que a sociedade fronteiriça procura romper" (NOGUEIRA, 2007, p. 32).

A fronteira, ao constituir-se como fato, transforma-se em fronteira como mecanismo do sistema capitalista. Tem-se então, na segunda metade do século XX, nessa região, um processo marcado pelo poder político dos Estados nacionais com repercussão direta sobre a população que vive no campo. Em 1963, o general Stroessner modifica o Estatuto Agrário de 1940, no Paraguai, permitindo a venda de terras a estrangeiros. No Brasil essa possibilidade permanece apenas no papel o Estatuto ${ }^{6}$ da Terra, promulgado em 1965. Aliado a isso, o uso da modernização agrícola e as leis trabalhistas fazem com que os proprietários de terras no Brasil evitem a permanência do trabalhador na propriedade para não originar vínculo empregatício. Isso leva muitos brasileiros a deixarem o Brasil e a buscarem no Paraguai a sua possibilidades de territorialização.

Esse fato evidencia a ideia de fronteira como movimento de transição, de contato, de integração, de porosidade, de fluxo e de complementaridade defendido por Haesbaert (2010), por Dorfman e Rosés (2005), por Santos (2004), entre outros. Essas ideias permitem perceber que, na Tríplice Fronteira (BR, PY e AR) se instalam diferentes etnias e que constroem escolas para atenderem as suas crianças e os seus jovens, igrejas para professarem a sua fé e casas de comércio para atenderem aos seus hábitos alimentares e de consumo em geral. Esses espaços constituem novas fronteiras, sem o sujeito deixar de participar da dinâmica territorial no contexto da Tríplice Fronteira. No limiar dessas fronteiras também se encontram os que estão em luta constante na busca por integração nos diferentes lados das fronteiras nacionais, os brasiguaios, por se encontrarem em situação de territorialização precária. Nesse sentido, o território usado pela sociedade local rege as manifestações da vida social.

Então se identificam na Tríplice Fronteira situações atípicas de deslocamento, em que migrantes de diferentes nacionalidades - paraguaios, argentinos, brasileiros, libaneses, chineses, coreanos, japoneses, alemães, italianos, entre outros -, se mobilizam entre os países como se estivessem transitando em bairros vizinhos.

Como limite, acordo, tratado, separação, divisa, distanciamento, corte e costura, essas são ideias de fronteira defendidas por Nogueira (2007), por Machado (1998), por Hissa, (2006), por Marques (2009) e por Raffestin (2011). Nesse patamar, visualiza-se a Tríplice Fronteira sendo formada pela área urbana entre as cidades de Foz do Iguaçu, Ciudad del Este e Puerto Iguazú. Então a Tríplice Fronteira (Representação 1) se constitui como uma área de

\footnotetext{
${ }^{6}$ Esse Estatuto previa uma política de intensificação e desenvolvimento da assistência à pequena propriedade e do cooperativismo que tornasse a pequena empresa agrícola economicamente viável.
} 
integração internacional recente (segunda metade do século XX) entre os três países - Brasil, Paraguai e Argentina.

Representação 1. Área urbana da Tríplice Fronteira

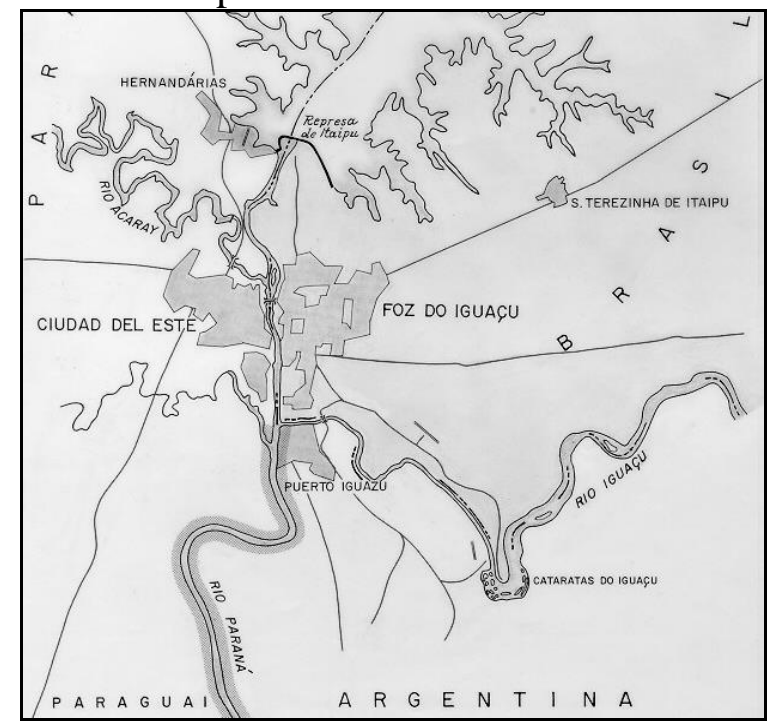

Fonte: Ministério das Relações Exteriores do Brasil. Disponível em: 〈http://www2.mre.gov.br/daa/amap1.html〉. Acesso em: 27 ago. 2011.

Essa integração que é mostrada na Representação 1 corrobora o pensamento de Mészáros (2011, p. 230): “Os representantes das seções mais poderosas do capital compreendem que não estão em posição de dispensar a proteção oferecida por seus Estados nacionais aos seus interesses vitais". Assim, Brasil, Argentina, Uruguai e Paraguai, “[...] após décadas de desconfiança entre si, [...] conseguiram firmar em 1991 [...] um arranjo diplomático que desaguaria no Mercado Comum do Sul, Mercosul“" (LESSA; ARRAES, 2011, p. 3). Tal acontecimento, como se sabe, alterou as relações internacionais nessa fronteira.

Ao norte da área urbana encontra-se a Represa de Itaipu, que configura a integração entre Brasil e Paraguai; ao sudeste, as Cataratas do Iguaçu, motivo de integração entre Brasil e Argentina.

Dessa forma, a região fronteiriça formada por esses três países - Brasil, Paraguai e Argentina -, por meio do Mercosul, faz a fronteira constituir-se em mecanismo de promoção e de proteção ao capital. Ao garantir tal mecanismo, a fronteira reflete sobre o sujeito brasiguaio, ao se manifestar como conflito, encontro versus desencontro, diferença, contradição, temporalidades distintas e também espoliação, que são ideias de fronteiras defendidas por Martins (2009), por Mélo (2004), por Albuquerque (2010) e por Bourdieu (1989). 
É na fronteira posta pelo capital que esta (a fronteira), vai constituir-se como fato e limite, com reflexo marcante sobre o ser humano que, neste estudo, está focado no aluno brasiguaio.

\section{A BUSCA POR SOBREVIVÊNCIA NA FRONTEIRA}

As famílias que hoje são conhecidas como brasiguaias, em gerações passadas elas fizeram parte do processo de migração europeia ao Brasil. Essas famílias vivem há gerações o processo de desterritorialização. Para Haesbaert (2001, p. 775 apud HAESBAERT, 2010, p. 250-251)

[...] para os mais pobres [...] é uma multi ou, no limite, a-territorialidade insegura, onde a mobilidade é compulsória [quando lhes é dada como possibilidade], resultado da total falta de [...] alternativas, de 'flexibilidade', em 'experiências múltiplas' imprevisíveis em busca da simples sobrevivência física cotidiana.

O movimento migratório entre territórios, nesse caso, não significa mobilidade social para essa camada da população, mas a sobrevivência física cotidiana.

$\mathrm{Na}$ Representação 2 estão localizados os departamentos que constituem o território paraguaio, regiões ocupadas por familiares dos alunos brasiguaios e que, em 2012, encontram-se matriculados em escolas brasileiras. Os Departamentos de Itapúa, de Caazapá e de Caaguazú fazem divisa com Alto Paraná. Isso significa que $80 \%$ das localidades em que brasileiros se instalaram encontram-se em Alto Paraná e em seu entorno.

Representação 2. Territorialização dos alunos brasiguaios no Paraguai

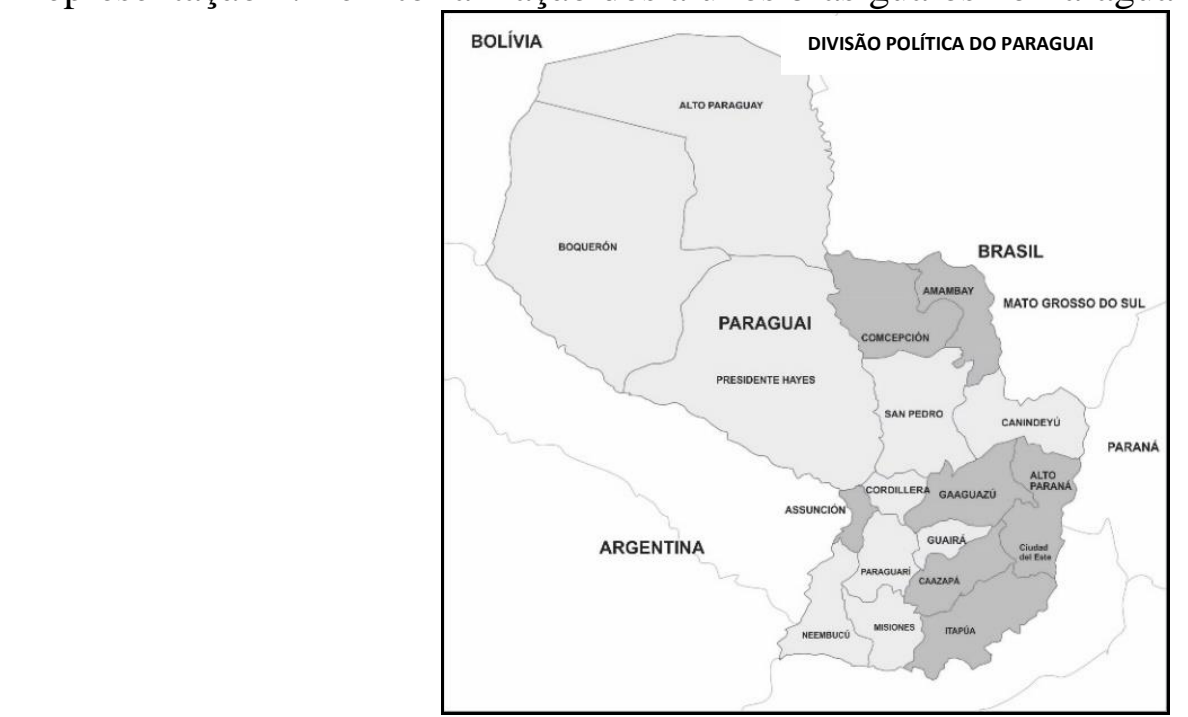

Fonte: Geografia do Paraguai $^{7}$. Adaptado por Margarete Frasson, nov. 2013

\footnotetext{
7 Disponível em: <http://www.mpdc.es/mapas/mapas/paraguay/paraguay. html>. Acesso em: 3 nov. 2013.
} 
Na Representação 2, os Departamentos em destaque por tom mais escuro são territórios ocupados por brasiguaios. Alto Paraná, cuja capital é Ciudad del Este, faz limite com o Estado do Paraná-Brasil e Misiones-Argentina, é o Departamento com maior ocupação pelos brasiguaios que se territorializaram no Paraguai pela política de integração nacional desenvolvida pelos governos dos dois países (BR, PY).

Nesse sentido, conforme mostra a Representação 2, compreendem-se as "[...] fronteiras nacionais como espaços sociais de integração, tensão e poder” (ALBUQUERQUE, 2010, p. 31).

Quanto ao movimento da população brasiguaia na fronteira, conforme mostram os prontuários dos filhos matriculados em escola pública brasileira em 2012, os pais emigraram ainda crianças, principalmente dos estados do Sul do Brasil (Rio Grande do Sul, Santa Catarina e Paraná, como mostra o registro de nascimento desses alunos brasiguaios, onde consta a naturalidade dos pais), estabelecendo-se em território paraguaio.

Dos territórios ocupados por brasiguaios, 51\% concentram-se no Departamento de Alto Paraná. Essa ocupação significativa é resultante do processo que se iniciou com a política de ocupação territorial desenvolvida pelo presidente Alfredo Stroessner, na chamada "Marcha em direção ao leste", paralela à "Marcha brasileira para o oeste", do tempo de Getúlio Vargas.

O movimento realizado por esses migrantes se dá pela busca de um lugar para produzir sua sobrevivência. A pequena propriedade rural, antes da instalação da agricultura química e mecânica, produzia o básico para a alimentação de quem nela morava, ou seja, “[...] a maioria das regiões produzia quase tudo de que necessitava para sua reprodução; produziase quase tudo em todos os lugares" (SANTOS, 2008a, p. 57), como, por exemplo, carne bovina, carne suína, carne de frango, hortaliças, legumes, cereais, entre outros. Além disso, mesmo que de forma artesanal, ainda era produzido sabão, açúcar, polvilho, queijo, instrumentos para os trabalhos diários... produtos que não era necessário comprar no mercado. Diante desse quadro cabe raciocinar como Gonçalves (1987, p. 18):

Ora, se um indivíduo tem todas as coisas de que precisa, não comprará nada. Por outro lado, na medida em que só faz uma única coisa, porque o trabalho se acha dividido, obviamente terá que adquirir as outras coisas de que não dispõe. Assim, o mundo das mercadorias cresce na medida em que cresce a divisão social do trabalho, isto é, a nossa sociedade, por ser produtora de mercadorias, precisa da divisão do trabalho. 
Quanto a essa especialização e mercantilização, Santos (2008a, p. 57) afirma: "Hoje, assistimos à especialização funcional das áreas e lugares, o que leva à intensificação do movimento [...]". O movimento entre lugares por esses migrantes há gerações, em busca de um lugar para produzir sua existência e nele poderem se estabelecer, esse mesmo movimento os exclui cada vez mais da possibilidade de suprir suas necessidades em espaço já ocupado pelo capital industrial. Um desses processos é o acesso à terra para produzir nela o de que necessitam. Essa restrição de espaço foi verificada no decorrer da análise das contas de luz das famílias dos alunos (Gráfico 1). Constataram-se situações de aparecerem cópias de uma mesma conta de luz em várias pastas, o que significa várias famílias morando em mesmo lote urbano, cuja luz é marcada por um único relógio. Isso se comprovou por constar o mesmo endereço e por observação in loco. Assim, "O mundo encontra-se organizado em subespaços articulados dentro de uma lógica global” (SANTOS, 2008a, p. 55).

Gráfico 1. Análise da conta de luz

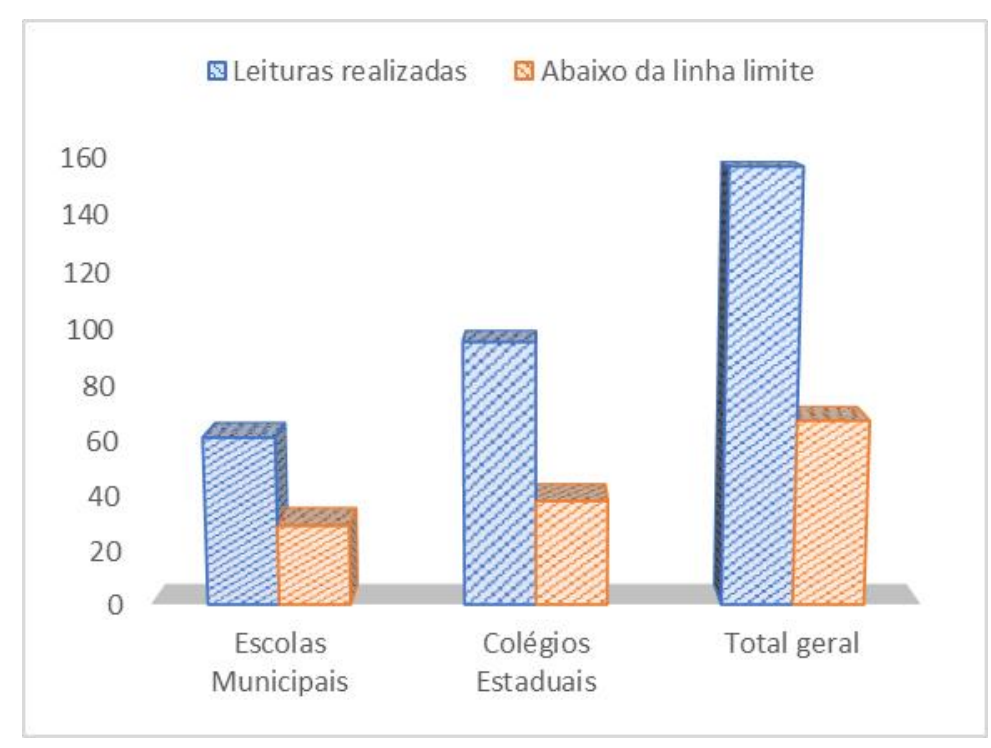

Organizado por Margarete Frasson, dez. 2013

Dentre os alunos que estudaram no Paraguai, dentre eles se identificam na condição de brasiguaios propriamente ditos (territorialização precária) aqueles cuja condição econômica está expressa na conta de luz: “[...] como o território é hoje um território nacional da economia internacional [...], a pobreza, hoje, é a pobreza nacional da ordem internacional" (SANTOS, 2008b, p. 74). Pelo “[...] reconhecimento de como um sistema se tece de relações (tendencialmente contraditórias), de como ele possui constitutivamente uma dinâmica" (BARATA-MOURA, 1997, p. 50, grifo do autor), é por essa dinâmica do sistema que se compreende o espaço de fronteira para os brasiguaios como "[...] a forma de estratos 
imbricados" (CERTEAU, 2008, p. 309). Pela análise das contas de luz chega-se ao seguinte resultado $^{8}$ (Gráfico 1):

Por esse critério do Gráfico 1 evidencia-se que nem todos os alunos que estudaram dos dois lados da fronteira (Brasil e Paraguai) se encontram em condições de busca pela sobrevivência diária na fronteira, ou seja, trabalhar hoje para comer amanhã. Há casos de famílias que se encontram territorializadas nos dois lados da fronteira. A mãe fica com os filhos do lado brasileiro para que possam estudar, e o pai continua com suas atividades econômicas no Paraguai - situação identificada no contato com os alunos.

De acordo com a Organização para a Cooperação e Desenvolvimento Econômico (OCDE-2012), em momentos de crise “[...] os indivíduos com educação superior estão em melhor posição para se defender dos seus efeitos mais severos". Os pais dos alunos brasiguaios encontram-se, porém, à margem, excluídos também desta possibilidade. Conforme dados ${ }^{9}$ levantados nos prontuários dos alunos, ficou demonstrado haver grande número de escolarizados com apenas o ensino fundamental incompleto. Salienta-se que essa informação, confrontada com a entrevista dos pais ${ }^{10}$, refere-se ao primeiro grado (primeira série ou ano, no Brasil). A partir dessa constatação, evidencia-se a existência de analfabetos e analfabetos funcionais inseridos na coluna do ensino fundamental incompleto. Infante (2000, p. 16) caracteriza o analfabeto funcional:

[...] es aquella persona que no puede participar en todas aquellas actividades en las cuales la alfabetización es requerida para la actuación eficaz en su grupo y comunidad y que le permiten, asimismo, continuar usando la lectura, la escritura y la aritmética al servicio de su propio desarrollo y del desarrollo de su comunidad.

Ao analisar os dados a partir da contribuição de Infante (2000) no Gráfico 2, primeira coluna, evidencia-se a existência dos analfabetos e dos analfabetos funcionais, ou seja, o número de pessoas que estão limitadas em suas funções no uso da leitura e escrita para utilizálas em seu desenvolvimento e o desenvolvimento de sua comunidade.

Para Arroyo (1997, p. 12), “A negação do saber interessou sempre à burguesia [...].

\footnotetext{
${ }^{8}$ Adotou-se como linha limite o consumo igual ou inferior a sessenta reais (R\$ 60,00). Essas informações referem-se a uma amostragem, uma vez que não foram analisadas cem por cento das contas de luz. Considera-se que muitas famílias vivem uma espécie de condomínio da energia elétrica, contas que foram excluídas da análise pelo valor apresentado, por não se constituírem dado relevante para a análise do objeto em estudo. Foi descartada a observação in loco de cem por cento dos casos detectados.

${ }^{9}$ Esses dados também fazem parte de uma amostragem, pois não se encontraram disponibilizados em todos os prontuários, fato que não permitiu o levantamento de cem por cento da escolaridade desses pais.

${ }^{10}$ Relato oral que se encontra na Dissertação de Mestrado em Geografia "Alunos Brasiguaios em Movimento na Tríplice Fronteira" - Unioeste / Campus Francisco Beltrão, 2014.
} 
Interessou ao Estado excludente, que prefere súditos ignorantes e submissos”.

$\mathrm{O}$ acesso à terra, à escolaridade, aos bens produzidos pela sociedade industrial, à cultura, entre outros, são elementos necessários à cotidianidade do indivíduo para sobreviver na sociedade de hoje. Quando falta o acesso a alguns desses bens, ele se mobiliza no espaço em busca desses meios.

Gráfico 2. Analfabetismo e demais graus de escolaridade

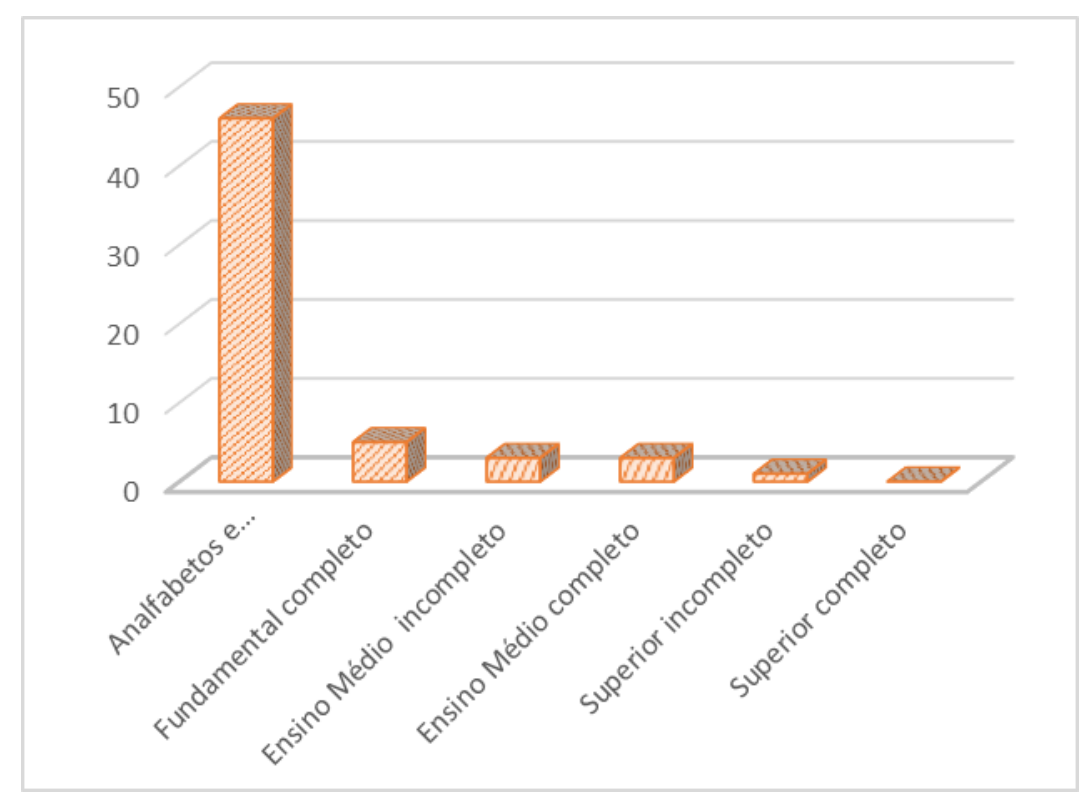

Organizado por Margarete Frasson, nov. 2013

Constata-se que "O sistema é tanto um meio como um fim. Como meio, denota um território, uma organização territorial, mas como fim conota uma ideologia da organização" (RAFFESTIN, 2011, p. 142). Excluído do sistema territorial pela política estrutural, o brasiguaio fica "Sem lugar próprio, sem visão globalizante, cega e perspicaz como se fica no corpo a corpo sem distância, comandada pelos acasos do tempo" (CERTEAU, 2008, p. 101). Utiliza a tática ${ }^{11}$ para sobreviver. Flutua na fronteira, em um espaço que se tornou "[...] um meio geográfico completamente diverso do que fora na aurora dos tempos históricos. Não pode ser comparado, qualitativa ou estruturalmente, ao espaço do homem anterior à Revolução Industrial” (SANTOS, 2008a, p. 48).

A perda do "senso de medida" (SANTOS, 2008a) pelo homem após a Revolução Industrial dificilmente será recuperado por esta sociedade que adota a educação como um serviço. Numa sociedade como a nossa,

${ }^{11}$ A tática é determinada pela ausência de poder (CERTEAU, 2008, p. 101, grifos do autor). 
O que se busca é uma estandardização da qualidade, da avaliação, da aprendizagem e a criação de "parâmetros" para tudo, como se tudo pudesse ser mensurável na educação. Trata-se de uma concepção "fordista" da qualidade [...]. (GADOTTI, 2007, p. 18).

O padrão de medida da qualidade utilizado pela concepção fordista, empregado na educação, aumenta os índices de defasagem idade-série ${ }^{12}$ entre os alunos brasiguaios. Exigese o cumprimento do padrão, no entanto a consciência social necessária aos menos favorecidos, que deveria fazer parte do processo educativo, inexiste, pois "Não é a consciência dos homens que determina [...] o seu ser [...] mas, inversamente, [é] o seu ser material [que] determina a sua consciência” (MARX apud BARATA-MOURA, 1997, p. 50).

Nesse sentido, sem acesso aos bens materiais, à escolaridade e à cultura, sem visão globalizante, cego e sem a perspicácia necessária para contruir sua materialidade histórica que teria por função determinar sua consciência social, ao projetar-se no espaço, o brasiguaio nem sequer percebe a presença da fronteira. A própria fronteira torna-se invisível. É nesse contexto e por influência dessas forças que se encontram os alunos brasiguaios em movimento na fronteira. Ele faz parte de fluxos considerados indesejáveis dos dois lados do limite internacional.

É o sistema fronteiriço que cria a invisibilidade para esses sujeitos, tanto quanto eles próprios se utilizam dessa invisibilidade ao dar o endereço de parentes ou amigos para fazer uso do Sistema de Saúde, ao arrumar trabalhos temporários de um lado e outro da fronteira, ao aceitar fazer permuta, ou seja, prestar serviços domésticos em troca de moradia, água e luz. São mecanismos de sobrevivência na fronteira que passou a ser também invisível a eles, quando não percebem o espaço por eles ocupado como sendo dois territórios com características culturais, sociais, econômicas diferentes.

\section{AS FRONTEIRAS E A INVISIBILIDADE DO ALUNO BRASIGUAIO}

Os estudos de fronteiras "[...] como espaços híbridos de saber e poder ajudam a ampliar o entendimento das experiências dos brasiguaios, situados próximos à fronteira política do Paraguai com o Brasil” (ALBUQUERQUE, 2010, p. 51). Como "Toda sociedade mostra sempre, em algum lugar, as formalidades a que suas práticas obedecem" (CERTEAU, 2008, p. 83). No espaço escolar é possível denominar de invisibilidade a estratégia criada pelo sistema nos procedimentos para a regularização de vida escolar, em curto período de tempo, a

\footnotetext{
12 Tema discutido no artigo "Alunos brasiguaios em movimento na Tríplice Fronteira: novas possibilidades, novos limites na integração do aluno brasiguaio". Revista Formação - UNESP, dez. 2012.
} 
que são submetidos os alunos brasiguaios. Considera-se, dessa forma, como sendo invisibilidade o fato de alunos concluírem várias séries em outro país e, no registro do histórico escolar ao ser matriculado em escola brasileira, não aparece o período lá estudado. Isso ocorre pela classificação e/ou retorno de série. Dessa maneira, ao mobilizar-se na fronteira, o aluno perde anos cursados no país vizinho, que é o que, neste estudo, é denominado invisibilidade. Evidencia-se, dessa forma, que [...] disputas por interesses econômicos e geopolíticos acionam vários elementos simbólicos de construção de uma autoimagem dos 'nós' e variadas representações dos 'outros' [...] (ALBUQUERQUE, 2010, p. 199).

A invisibilidade também é utilizada pelo aluno brasiguaio em sala de aula. Isso pode ser entendido segundo as palavras de Certeau (2008, p. 100-101):

[...] chamo de tática a ação calculada que é determinada pela ausência de um próprio. [...] Ela não tem, portanto, a possibilidade de dar a si mesma um projeto global nem de totalizar o adversário num espaço distinto, visível e objetivável. Ela opera golpe por golpe, lance por lance. [...] Consegue estar onde ninguém espera. É astúcia (grifos do autor).

Ainda de acordo com Certeau (2008, p. 101), “[...] a tática é a arte do fraco [...] a astúcia é possível ao fraco, e muitas vezes apenas ela, como 'último recurso"”. A invisibilidade criada pelos interesses econômicos geopolíticos é utilizada pelo aluno brasiguaio como astúcia para conviver no contexto da sala de aula, na escola, que enquanto instituição disciplinar, hierarquiza, homogeneíza, exclui para atender o sistema em vigor. Essa tática ou astúcia permite a esses alunos uma convivência no espaço escolar de maneira aparentemente harmônica, por encontrarem-se perante os olhos de professores e colegas de classe de forma invisível, apresentando problemas de aprendizagem que se refletem principalmente no momento das avaliações escritas, pois então necessitam efetivamente saber expressar seu conhecimento no idioma formal do país.

$\mathrm{Na}$ busca por compreender essa invisibilidade foram elaborados os Gráficos 3 e 4. Os dados aí apresentados levam à reflexão de que o sistema educacional colocado em prática, ao organizar os processos de "[...] compreensão da realidade como universal e única, tomando por base um saber formal e abstrato distanciado do aluno, de sua vida e experiência" (NUNES, 2011, p. 209), leva o professor que atua em escola de fronteira a não visualizar a existência desse aluno estrangeiro no espaço escolar. As fronteiras são, por assim dizer, concebidas cotidianamente em diferentes campos da vida. Constituem-se realidades vivas que concebem um campo de aprendizados e interações sociais, políticas, econômicas, culturais e 
ideológicas.

Gráfico 3. Situação dos alunos em sala de aula

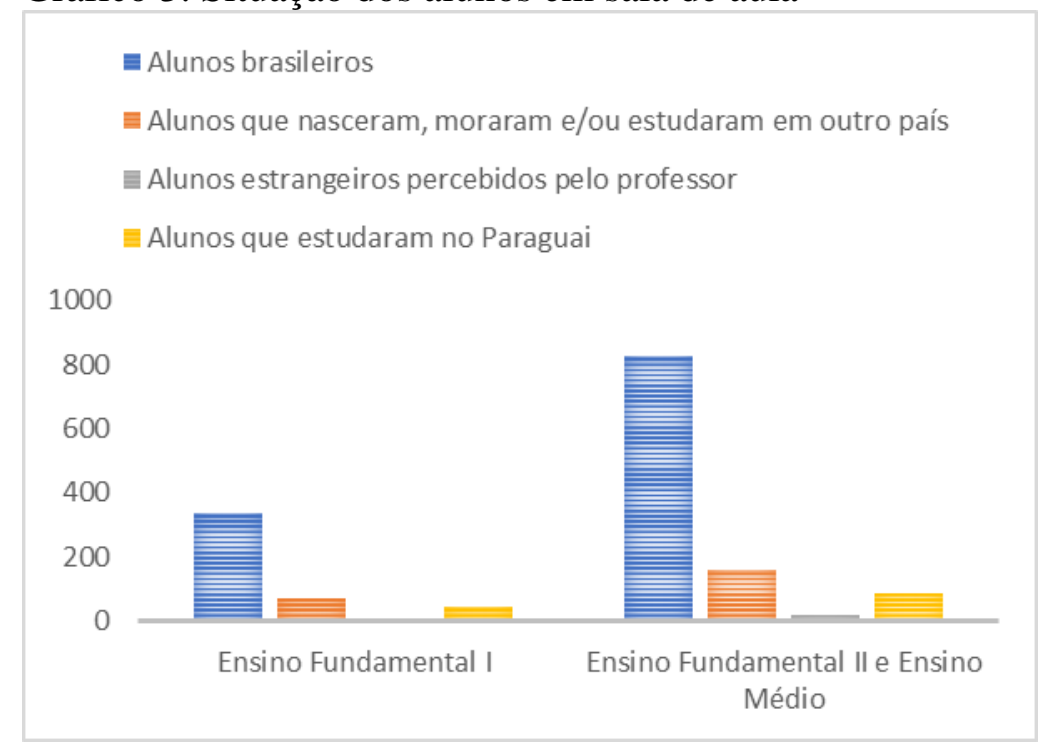

Organizado por Margarete Frasson, nov. 2013

O Gráfico 3, ao estabelecer um comparativo entre a quantidade de alunos brasileiros com os que nasceram, moraram e/ou estudaram em outro pais e também ao estabelecer os alunos estrangeiros percebidos pelo professor e com o número de alunos que apresentam experiência escolar no Paraguai e no Brasil, demonstra a política educacional que opera no bloco econômico MERCOSUL.

Dessa forma, Santos (2008a, p. 54-55) evidencia:

A busca da explicação das transformações passa pela compreensão dos grandes grupos de variáveis [...]. Tais variáveis são interdependentes, umas sendo causa e/ou conseqüência de outras, não tendo, portanto, real valor se não forem analisadas em conjunto.

Os mecanismos criados na organização do sistema escolar formam espaços justapostos na instituição, sem vasos comunicantes. Devido a isso, os conteúdos disciplinares ministrados por diferentes professores na sala de aula, a secretaria que recebe a documentação do aluno, a supervisão escolar e a direção realizam atividades isoladas uns dos outros, fato que leva esse aluno a ser visto apenas em sua chegada, quando a secretaria o recebe e repassa à supervisão a informação, e esta aos professores. Realizados os trâmites legais, o aluno brasiguaio, por se comunicar verbalmente no idioma local, segue o curso, não sendo mais percebido como estrangeiro. Então, a partir desse momento, cabe somente a ele administrar o processo de integração preconizado pela política mercosulina. Assim, “[...] o agir simbólico se confunde com as formas culturais de apropriação e utilização da técnica" (SANTOS, 2006, p. 53) 
utilizada pela escola ao inserir o aluno no processo educacional, em espaço fronteiriço. Evidencia-se que "[...] o mundo em nossa volta está repartido em fragmentos mal coordenados, enquanto as nossas existências individuais são fatiadas numa sucessão de episódios fragilmente conectados" (BAUMAN, 2005, p. 18-19).

Os fragmentos mal coordenados e mal conectados conduzem à invisibilidade, como mostra o Gráfico 4. Os dados desse gráfico demonstram que há invisibilidade dos alunos brasiguaios perante os olhos do professor. De acordo com Santos (2008a, p. 68), "Nossa visão depende da localização em que se está”. As edificações disciplinares (escola, cadeia e hospital no início da idade moderna, quando o capitalismo começa a se espraiar) eram construídas de forma que a pessoa que estivesse no comando pudesse, de um ponto estratégico, ver tudo o que se passava na instituição. Os dados demonstram que não é o professor que se encontra no espaço de controle da educação, senão que o olhar de controle está presente é no currículo escolar, no livro didático e na legislação que se aplica no interior da escola. Nesse sentido, o SEM recebe, proveniente dos países globalizadores, recomendações (incumbências) sobre educação e, posteriormente, propõe isso aos Estados-Partes do MERCOSUL. Deduz-se, então, que o controle da educação dos países desse bloco econômico encontra-se com os países centrais.

Gráfico 4. Identificação e percepção de alunos migrantes

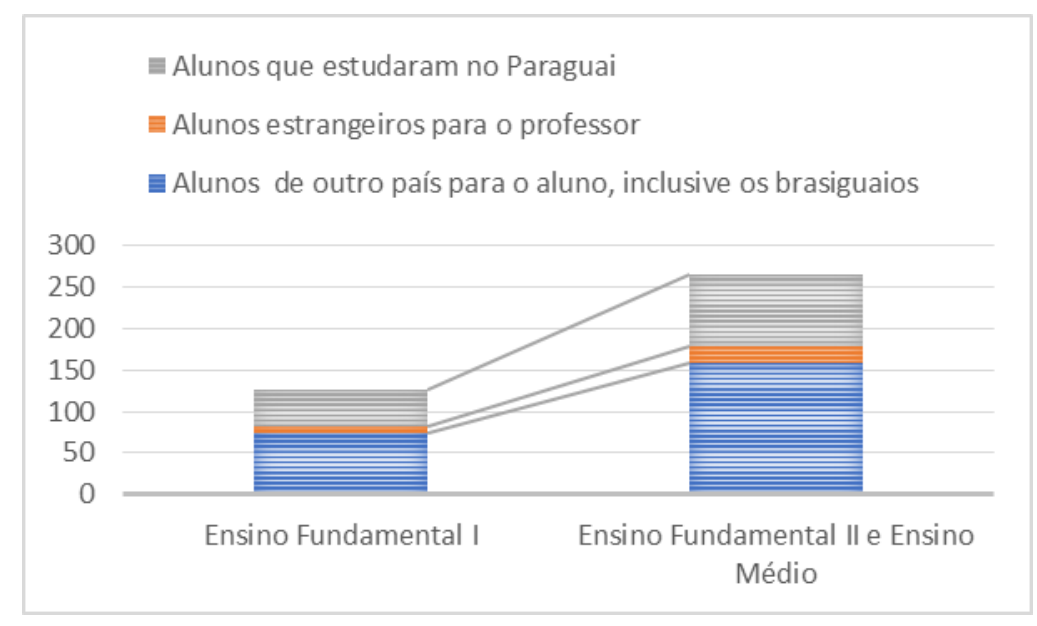

Organizado por Margarete Frasson, nov. 2013

Da parte superior do Gráfico 4 foram excluídos os alunos que estudaram e/ou moraram em outros países que não fosse o Paraguai. Permanecem na parte superior desse gráfico apenas os alunos com experiência de haverem estudado no Paraguai e de, em 2012, estarem matriculados em escola brasileira.

Sobre a parte intermediária do gráfico, referente aos alunos estrangeiros percebidos 
pelos professores, cabe um alerta. Na segunda coluna, a quantidade maior de alunos estrangeiros apontados pelos professores no Fundamental II e Ensino Médio se deve ao fato de alguns professores, no momento de preencherem os formulários, terem consultado as turmas em que estavam presentes - fosse apenas por seu conhecimento e memória, o número seria menor.

Por fim, a base do Gráfico 4 contém os alunos que nasceram, moraram e/ou estudaram em outro país, inclusive os brasiguaios.

O Gráfico 4 evidencia que os alunos migrantes no contexto da sala de aula não são percebidos em suas características identitárias. Nessa situação, os alunos são vistos como iguais. Para Candau (2007, p. 400), “[...] temos direito a reivindicar a igualdade sempre que a diferença nos inferioriza e temos direito de reivindicar a diferença sempre que a igualdade nos descaracteriza". Assim, ao não serem vistos, os alunos encontram-se descaracterizados. Nesse sentido, não recebem o atendimento necessário para viver nesse espaço marcado pela alteridade.

\section{CONSIDERAÇÕES FINAIS}

O Estado e o Mercado, em suas relações em um processo de fronteira, exercem pressões sobre os indivíduos. Fazem com que se movimentem para um lado e outro da fronteira nacional, na busca de possibilidades que os auxiliem a vencer os limites impostos à sua sobrevivência nesse espaço. A fronteira para o capital é uma proteção, um mecanismo que se utiliza da própria fronteira para o processo de acumulação. A fronteira como fato, essa, por sua vez, justifica e torna invisível o processo de espoliação ao brasiguaio no contexto social.

$\mathrm{O}$ aluno brasiguaio ${ }^{13}$ é um sujeito que convive no espaço de contradição entre duas culturas, uma sendo a que ele traz consigo de outro país e a outra sendo aquela que se apresenta no espaço de convivência da escola atual. Assim, o aluno brasiguaio pode ser também compreendido também como "[...] sujeito ou grupo social que possui precário domínio sobre o espaço" (FABRINI, 2011, p. 98). Encontra-se no contexto do bloco econômico Mercosul, na confluência de diferentes Estados nacionais.

No contexto da sala de aula, ele (aluno brasiguaio) precisa apagar as evidências de traços de cultura híbrida adquirida junto à família e à escola, como parte do processo

\footnotetext{
${ }^{13}$ São descendentes de brasileiros (peões, arrendatários, meeiros), cuja mão de obra foi utilizada pelo processo de modernização agrícola no Oeste paranaense (BR) direcionado (FLEISCHFRESSER, 1988) pelo Estado através de medidas de política econômica no processo de "limpeza dos terrenos", para, posteriormente, o "capital" fazer uso das inovações químicas e mecânicas em seu processo de produção. No Paraguai desempenharam esse mesmo papel. São gerações que migram de um espaço a outro em busca de melhores condições de vida. (SCHLOSSER; FRASSON, 2012, p. 13).
} 
educacional no contexto dos dois territórios (Brasil e Paraguai). Para se integrar na escola pública brasileira, apresenta dificuldades em acompanhar as atividades desenvolvidas na escola por não entender o significado do que está sendo solicitado. Então isso os leva a atitudes de silenciamento, tornando-os invisível. Nesse caso, essa invisibilidade é criada pelas relações marcadas por normas homogeneizantes, propostas pelos Estados-Nações, em sua soberania, e pelo Bloco Econômico, inserido em contexto global. Assim, "O brasiguaio vivencia e sintetiza a contraditória experiência de conflito e integração na zona de fronteiras" (ALBUQUERQUE, 2010, p. 235).

Mesmo não sendo caracterizável como brasileiro e tampouco como paraguaio, trata-se de um sujeito portador de uma cultura híbrida. É também um sujeito pleno de direitos, mesmo assim, no entanto, o contexto do sistema educacional do Bloco Econômico cria barreiras ao tempo de vida escolar do aluno brasiguaio, pois faz com que permaneça mais tempo na escola sob a alegação de não estar de acordo com o padrão de qualidade previsto para cada ano de estudo. Depois de realizados os trâmites legais, o aluno brasiguaio, por se comunicar verbalmente no idioma local, segue o curso, não sendo mais percebido como migrante, ficando invisível em suas necessidades de aprendizagem como aluno estrangeiro.

\section{REFERÊNCIAS BIBLIOGRÁFICAS}

ALBUQUERQUE, José Lindomar C. A dinâmica das fronteiras: os brasiguaios na fronteira entre o Brasil e o Paraguai. São Paulo: Annablume, 2010.

ARROYO, Miguel G. (Org.). Da escola carente à escola possível. São Paulo: Edições Loyola, 1997.

BARATA-MOURA, José. Materialismo e subjetividade: estudos em torno de Marx.

Lisboa: 1997.

BAUMAN, Zygmunt. Identidade: entrevista a Benedetto Vecchi. Tradução Carlos Alberto Medeiros. Rio de Janeiro: Jorge Zahar, 2005.

BOURDIEU, Pierre. O poder simbólico. Trad. Fernando de Tomaz. Lisboa: Difel. 1989.

CANDAU, Vera Maria. Educação em direitos humanos: desafios atuais. In: SILVEIRA, Rosa Maria Godoy et al. Educação em direitos humanos: fundamentos teórico-metodológicos. João Pessoa, PB: Editora Universitária, 2007. p. 399-414.

CERTEAU, Michel de. A invenção do cotidiano: arte de fazer. Trad. Ephraim Ferreira Alves. 14. ed. Petrópolis, RJ: Vozes, 2008. p. 35-351.

DORFMAN, Adriana; ROSÉS, Gladys Teresa. Regionalismo fronteiriço e o acordo para os nacionais fronteiriços brasileiros uruguaios. In: OLIVEIRA, Tito C. M. de (Org.). Território sem limites: estudos sobre fronteiras. Campo Grande, MS: Ed. UFMS, 2005. p.195- 228. FABRINI, João E. Território, classe e movimentos sociais no campo. Revista da ANPEGE, v. 7, n. 7, p. 97-112, jan./jul. 2011.

FLEISCHFRESSER, Vanessa. Modernização tecnológica da agricultura. Curitiba, PR: Livraria do Chain: COCITEC:IPARDES, 1988.

GADOTTI, Moacir. O Mercosul Educacional e os desafios do século 21. Brasília, DF: Instituto Nacional de Estudos e Pesquisas Educacionais Anísio Teixeira, 2007. 
GONÇALVES, Carlos Walter Porto. Reflexões sobre Geografia e Educação: notas de um debate. Terra Livre, São Paulo, v. 2, p. 9-42, 1987.

HAESBAERT, Rogério. O mito da desterritorialização: do "fim dos territórios" à multiterritorialidade. 5. ed. Rio de Janeiro: Bertrand Brasil, 2010.

HISSA, C. E. V. A mobilidade das fronteiras: inserções da geografia na crise da modernidade. Belo Horizonte, MG: UFMG, 2006.

INFANTE, Isabel. Alfabetismo funcional em siete países de América Latina. Santiago: Unesco, 2000. Disponível em: <http://unesdoc.unesco. org/images/pdf〉. Acesso em: 18 dez. 2013.

LESSA, Antônio Carlos; ARRAES, Virgílio Caixeta. Mercosul: a trajetória em formação. Boletim Meridiano 47, v. 12, n. 125, p. 18-24, maio/jun. 2011.

MACHADO, Lia Osório. Limites, fronteiras, redes. In: STROHAECKER, A. et al. (Orgs.). Fronteiras e espaço global. Porto Alegre, RS: AGB-Porto Alegre, 1998. p. 41-49.

MARQUES, Denise Helena França. Circularidade na fronteira do Paraguai e Brasil: o estudo de caso dos "brasiguaios". 2009. Tese (Doutorado em Demografia) - Universidade Federal de Minas Gerais, Faculdade de Ciências Econômicas, Belo Horizonte, 2009.

MARTIN, André Roberto. Fronteiras e nações. 2. ed. São Paulo: Contexto, 1994.

MARTINS, José de Souza. Fronteira: a degradação do outro nos confins do humano. São Paulo: Contexto, 2009.

MÉLO, José Luiz Bica. Fronteiras: da linha imaginária ao campo de conflitos. Sociologias, Porto Alegre, n. 11, jan./jun. 2004.

MÉSZÁROS, István. Para além do capital: rumo a uma teoria da transição. Trad. Paulo Cezar Castanheira e Sérgio Lessa. São Paulo: Boitempo, 2011.

NOGUEIRA, Ricardo José Batista. Fronteira: espaço de referência identitária? Ateliê Geográfico, Goiânia, v. 1, n. 2, p. 27-41, dez. 2007.

NUNES, Flaviana Gasparotti. Projetos de formação escolar para escolas em áreas de fronteira. Revista da ANPEGE, v. 7, n. 1, número especial, p. 205-216, out. 2011.

RAFFESTIN, Claude. Por uma geografia do poder. São Paulo: Khedir Editora, 2011. SANTOS, Maria Elisa Pires. O cenário multilíngüe/multidialetal de fronteira e o processo identitário de alunos brasiguaios no contexto escolar. 2004. 253 p. Tese (Doutorado em Lingüística Aplicada) - Universidade Estadual de Campinas, Campinas, 2004.

SANTOS, Milton. A natureza do espaço: técnica e tempo, razão e emoção. 4. ed. São Paulo: Editora da Universidade de São Paulo, 2006.

Metamorfoses do espaço habitado: fundamentos teóricos e metodológicos da geografia. 6. ed. São Paulo: EDUSP, 2008a.

Por uma outra globalização: do pensamento único à consciência universal. 16. ed.

Rio de Janeiro: Record, 2008b.

SCHLOSSER, Marli Terezinha Szumilo.; FRASSON, Margarete. Alunos Brasiguaios em movimento na Tríplice Fronteira: novas possibilidades e novos limites na integração do aluno brasiguaio. Revista Formação Online, v. 19, p. 3-31, 2012.

Recebido em agosto de 2014.

Aceito em agosto de 2017. 